Copyright (C) 2012 IEEE. Personal use of this material is permitted. Permission from IEEE must be obtained for all other uses, in any current or future media, including reprinting/republishing this material for advertising or promotional purposes, creating new collective works, for resale or redistribution to servers or lists, or reuse of any copyrighted component of this work in other works. 


\title{
Effects of Iron-Core Topology on Inrush Currents in Three-Phase Multi-Leg Power Transformers
}

\author{
Paul S. Moses, Student Member, IEEE, Mohammad A. S. Masoum, Senior Member, IEEE \\ and Moayed Moghbel, Student Member, IEEE \\ Department of Electrical and Computer Engineering, Curtin University, Perth, WA, Australia \\ paul.s.moses@gmail.com; m.masoum@curtin.edu.au
}

\begin{abstract}
This paper investigates the inrush currents of threephase (a)symmetric multi-leg transformer cores considering magnetic core structure (e.g., three-leg vs. five-leg) and switching effects (e.g., recloser operating). The electromagnetic steady-state and transient behavior of three-phase transformers significantly differs from single-phase transformer operation mainly because of the unique flux coupling interactions in multi-leg and asymmetric core structures. A recently developed three-leg nonlinear transformer core model is applied to this study which considers the influence of magnetic hysteresis, flux couplings in the core-structure and nonsinusoidal operation in three-phase transformers. Simulations results for multi-leg (e.g., three-leg and five-leg) transformer cores demonstrating inrush current behavior based on the model are presented and discussed.
\end{abstract}

Index Terms-Inrush current, nonlinear transformer model.

\section{INTRODUCTION}

$\mathrm{P}$ OWER TRANSFORMERS are vital ubiquitous links in power distribution and transmission systems throughout the world [1]. Their proper maintenance for assuring high reliability is essential for a low interruption and economic power system operation. Although newer technologies (e.g., power electronic transformers [2, 3]) are being investigated to replace century year old based transformer designs, this is unlikely to happen for many decades, even with the proposed smart grid overhaul, because of their widespread use and inherent reliability in the simplicity of conventional transformer design.

In light of the future of transformers operating in an environment of growing network complexity (e.g., smart grids $[4,5])$, there is a push toward developing better transformer models to study new operational scenarios, protection and running performance $[6,7]$. To that end, there has been a significant improvement in recent years in developing threephase multi-leg transformer models. This is important since the electromagnetic steady-state and transient behavior of three-phase transformers significantly differs from that of single-phase transformer operation.

Specifically, the multiple flux paths and magnetic couplings in multi-leg cores exhibit totally different behavior from "perphase" single-phase transformer modeling studies that ignores the magnetic core geometry. Furthermore, existing studies also do not include or oversimplify the complicated magnetic hysteresis effects (e.g., major and minor loops) leading to further discrepancies.

This paper focuses on transformer inrush current behavior in three-phase multi-leg (e.g., three-leg and five-leg) transformer cores and how they can be influenced by the core structure and external switching effects (e.g., auto-recloser operation). The study is carried out with a newly developed time-domain nonlinear model $[8,9]$ augmented for (a)symmetric multi-leg transformer cores.

\section{NONLINEAR MOdel of Distribution TRANSFORMER}

The electromagnetic behavior of three-phase multi-leg transformers depends mainly on the magnetic interactions and nonlinearities in the ferromagnetic iron-core structure. Many three-phase transformer studies are based mainly on singlephase transformer models that only amount to a "per-phase" representation. Inherent in per-phase studies is the assumption of isolated magnetic cores for each phase that do not interact with one another. For three-phase transformers, this approach would only be valid for a three-phase transformer "bank" (i.e., three single-phase transformers) that have isolated cores and may share a tank. A simple consequence of the magnetic circuit is that if a single-phase ac voltage is applied to only one of the coil windings, voltages will be induced in the other disconnected phases due to ac fluxes "spilling over" into adjacent core-legs.

\section{A. Three-Phase Transformer Modeling}

The magnetic interactions in multi-leg cores are very slowly being introduced into main stream three-phase transformer models. Virtually all commercial computer simulation tools have yet to adopt such models into their libraries and opt for the simpler per-phase equivalent models. Therefore, the emerging three-phase transformer models attempting to include multi-leg core topologies are being custom developed by researchers. One such model has recently been developed and validated for PSPICE which considers the electric and magnetic circuits inherent in the core geometry (e.g., threeleg, five-leg cores) [8-10].

Seldom considered is the fact that some core-geometries can be asymmetric with different magnetizing behavior in each of the core-legs. This is because of different leg and yoke sizes such as that present in the three-leg cores (i.e., the center leg being shorter). This is considered in the implemented model with detailed representations of ferromagnetic nonlinearities (e.g., hysteresis and saturation). Fig. 1 summarizes different types of three-phase multi-leg transformer core topologies. 


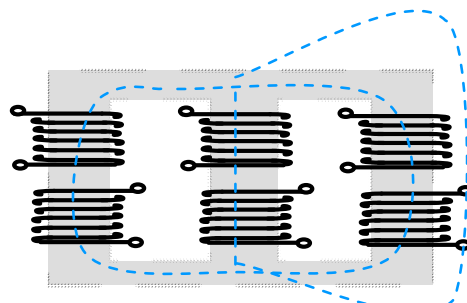

CORE FORM (STACKËD)

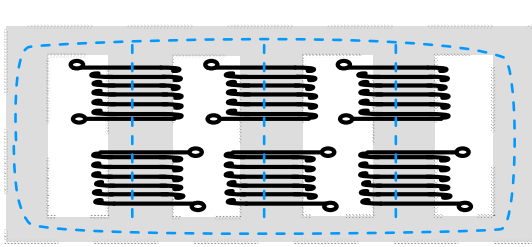

5-LEGGED STACKED CORE

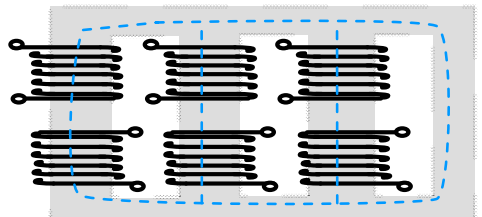

4-LEGGED STACKED CORE
- Core-form: least amount of core material

- Stacked lamination

-Worst problem: zero sequence fluxes cannot circulate and forced through air and tank -Tank heating problem

-Magnetic path for zero sequence flux

- More symmetric core - Often used for lowprofile for shipping or visual appearance in urban substations

-Provides magnetic path for zero sequence flux

- Outer phases do not exhibit like behavior

-Not very common
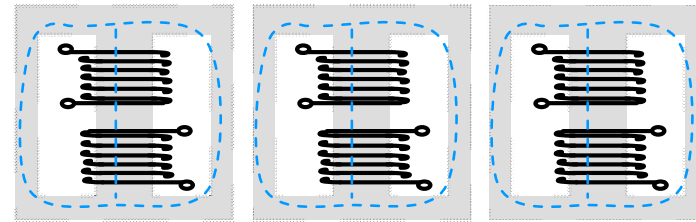

TRIPLEX CORE (WOUND OR STACKED)

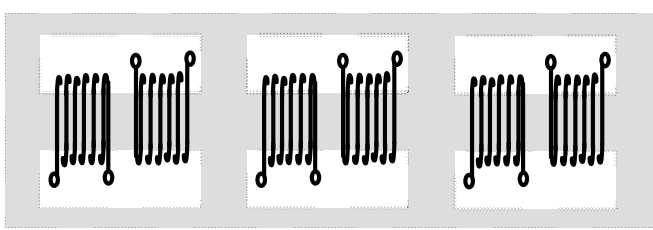

SHELL FORM (STACKED)

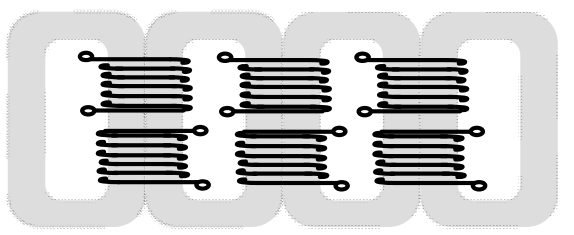

5-LEGGED WOUND CORE
- Similar magnetic characteristics to $3 \times 1 \varnothing$ transformer banks - Cores share same tank but magnetically isolated.

-Zero sequence flux circulates in each core

- minimal tank heating

-Shell-form: provides magnetic path for zero sequence flux

- Better suited for unbalanced operation

-Stacked laminations

- Four concentrically laminated cores

- Only adjacent phases are directly linked magnetically

-Virtually no magnetically coupling in outer windings

-Zero sequence fluxes contained in core

-minimal tank heating

Fig. 1. Overview of three-phase multi-leg transformer core types and magnetic circuit topologies. (Information in this figure is largely derived from Ref. [11]).

\section{B. Duality Principle}

The duality principle is employed by in the model by implementing electric and magnetic equivalent circuits for the three-phase multi-leg transformer core $[12,13]$. The nodal circuit equations for the coupled electromagnetic circuits are solved in time domain through iterative numerical techniques (e.g., Newton-Raphson). The transformer winding connections together with the source and load configuration comprise the electric equivalent circuit. This includes internal transformer impedances such as the leakage flux inductances and core-loss resistances derived from open and short circuit test data.

The magnetic circuit represents multiple core flux paths, nonlinear reluctances in the ferromagnetic material and magnetomotive forces developed in multi-leg cores [14]. It also includes the effects of zero-sequence fluxes possibly permeating tank and air gaps containing the iron-core. Individual magnetization nonlinear saturation functions for each core-leg are implemented to model the asymmetric leg magnetizing behavior. The solution of the magnetic circuit is made possible in electric circuit simulator software by again employing the duality principle by representing fluxes as currents, $\mathrm{mmfs}$ as voltages and reluctances as resistances.

\section{Electric Equivalent Circuit}

The electric circuit voltage relationships of three-phase star/star connected windings (Fig. 2) can be written as follows

$$
\begin{aligned}
& v_{p, x}(t)=R_{p, x} i_{p, x}(t)+L_{p, x} \frac{d i_{p, x}(t)}{d t}+\frac{d \lambda_{p, x}(t)}{d t} \\
& v_{s, x}(t)=R_{s, x} i_{s, x}(t)+L_{s, x} \frac{d i_{s, x}(t)}{d t}+\frac{d \lambda_{s, x}(t)}{d t}(x=a, b, c)
\end{aligned}
$$

where the voltages, currents and flux linkages are $v_{p, x}, v_{s, x}, i_{p, x}$ $i_{s, x}, \quad \lambda_{p, x}=N_{p} \phi_{x}\left(f_{x}\right)$ and $\lambda_{s, x}=N_{s} \phi_{x}\left(f_{x}\right)$ respectively for the primary and secondary windings. Internal transformer impedances for the respective primary/secondary windings $R_{p, x}, R_{s, x}, L_{p, x}$ and $L_{s, x}$ are the respective winding resistances and leakage flux inductances. The induced voltages based on flux linkages $\lambda_{p, x}$ and $\lambda_{s, x}$ are driven by controlled voltage sources using the rate-of-change of fluxes (Faraday's Law) developed in the magnetic circuit. This paper's study results are based on parameters obtained from measurements of a 1.6 $\mathrm{kVA}, \quad 50 \mathrm{~Hz}, \quad 440 \sqrt{3} / 55 \sqrt{3} \mathrm{~V}$ three-phase three-leg transformer [8].

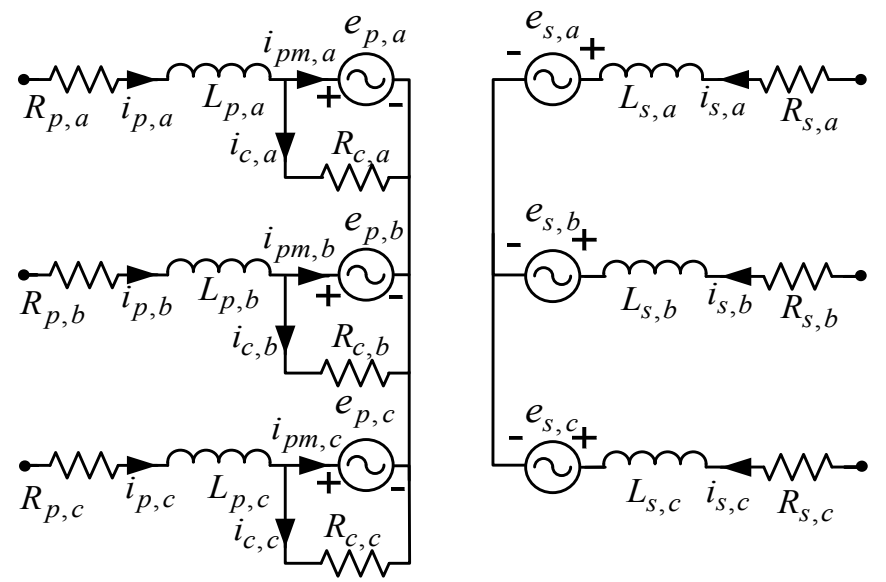

Fig. 2. Three-phase electric equivalent circuit model for star/star connection 


\section{Magnetic Equivalent Circuit and Hysteresis Modeling}

The magnetic circuit fluxes including the mutual magnetic couplings in the core-legs are governed by Kirchoff's Current Law that also applies to magnetic circuit fluxes. For a threeleg transformer core, the flux behavior can be expressed as

$$
\sum_{x=a, b, c} \phi_{x}+\phi_{0}=0
$$

where $\phi_{a}, \phi_{b}$ and $\phi_{c}$ are the core-leg fluxes, and the zerosequence flux path through air or tank structures is $\phi_{0}$.

The ferromagnetic nonlinearities of the core are modelled as flux sources (using current sources) with their nonlinearities dependent on their own MMF drops. Saturation functions are employed to control these flux sources based on magnetizing characteristics obtained from a three-leg transformer. The following saturation functions make use of dynamic hysteresis mathematical models developed in $[8,15]$ to model the complex major and minor hysteresis loop formations under transient and steady-state operation:

$$
\begin{gathered}
\frac{d \phi_{x}}{d t}=\frac{d f_{x}}{d t}\left[\rho_{x}+\frac{\phi_{x}^{-}\left(f_{x}\right)-\phi_{x}}{\phi_{x}^{-}\left(f_{x}\right)-\phi_{x}^{+}\left(f_{x}\right)}\left(\frac{d \phi_{x}^{+}\left(f_{x}\right)}{d f_{x}}-\rho_{x}\right)\right] \\
\text { if } \frac{d \phi_{x}}{d t} \geq 0
\end{gathered}
$$$$
\frac{d \phi_{x}}{d t}=\frac{d f_{x}}{d t}\left[\rho_{x}+\frac{\phi_{x}-\phi_{x}^{+}\left(f_{x}\right)}{\phi_{x}^{-}\left(f_{x}\right)-\phi_{x}^{+}\left(f_{x}\right)}\left(\frac{d \phi_{x}^{-}\left(f_{x}\right)}{d f_{x}}-\rho_{x}\right)\right]
$$$$
\text { if } \frac{d \phi_{x}}{d t}<0 \quad(x=a, b, c)
$$

where leg fluxes are $\phi_{x}$ that are supported by winding $\mathrm{mmf}$ potentials $f_{x}, \phi_{x}^{+}\left(f_{x}\right)$ and $\phi_{x}^{-}\left(f_{x}\right)$ are the required model functions for the upper and lower segments of the major hysteresis loop defined for each core-leg, and the fully saturated region slope is defined by $\rho_{x}$. Nonlinear functions $\phi_{x}^{+}\left(f_{x}\right)$ and $\phi_{x}^{-}\left(f_{x}\right)$ are defined and curve fitted to measured major hysteresis loops in each core-leg obtained in [8],

$$
\begin{aligned}
& \phi_{x}^{+}\left(f_{x}\right)=\operatorname{sgn}\left(f_{x}-\sigma_{x}\right) \cdot \alpha_{x} \log _{e}\left(\beta_{x}\left|f_{x}-\sigma_{x}\right|+1\right) \\
& \phi_{x}^{-}\left(f_{x}\right)=\operatorname{sgn}\left(f_{x}+\sigma_{x}\right) \cdot \alpha_{x} \log _{e}\left(\beta_{x}\left|f_{x}+\sigma_{x}\right|+1\right) \quad(x=a, b, c)
\end{aligned}
$$

These functions constants $\alpha_{x}$ and $\beta_{x}$ scale the characteristic horizontally and vertically for curve fitting, and $\sigma_{x}$ shifts the curve horizontally affecting the loop widths [8]. The slope functions dependent on (4) is

$$
\frac{d \phi_{x}^{ \pm}\left(f_{x}\right)}{d f_{x}}=\frac{\alpha_{x} \beta_{x}}{\beta_{x}\left|f_{x} \mp \sigma_{x}\right|+1} \quad(x=a, b, c)
$$

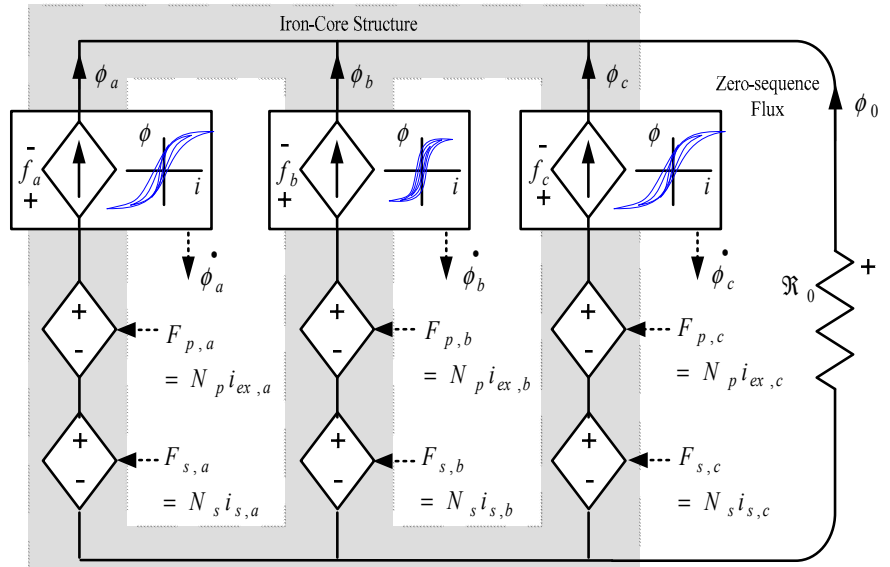

Fig. 3. Nonlinear asymmetric three-phase (three-leg) magnetic circuit model

\section{SimUlation RESUlts}

The model described in Section II is implemented to simulate the effects of different inrush conditions brought upon by variations in transformer core designs and switching operations of reclosers. Results are presented in Figs. 4 to 7 and are discussed in Section IV. A $440 \sqrt{3} \mathrm{~V}$ three-phase feeder supplies a dry-type $1.6 \mathrm{kVA}, 50 \mathrm{~Hz}, 440 \sqrt{3} / 55 \sqrt{3} \mathrm{~V}$ three-phase transformer.

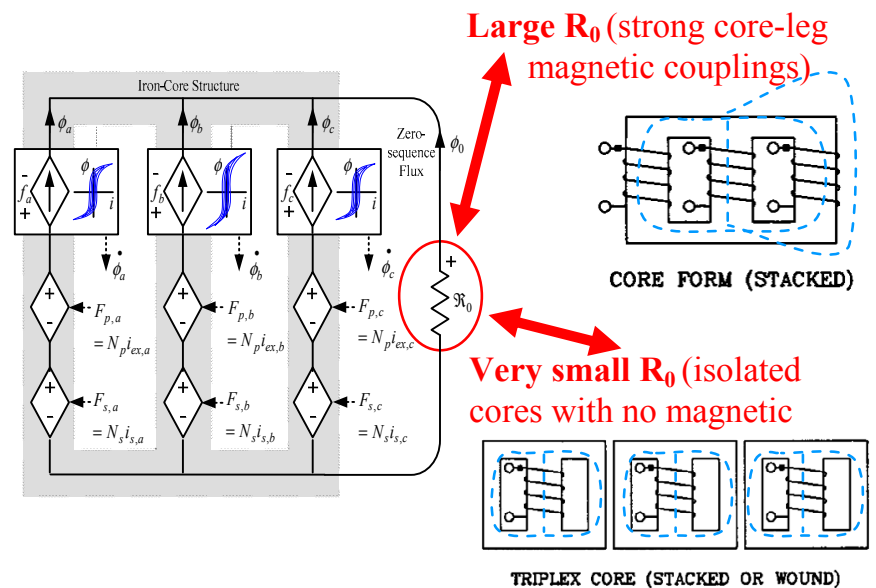

(a)

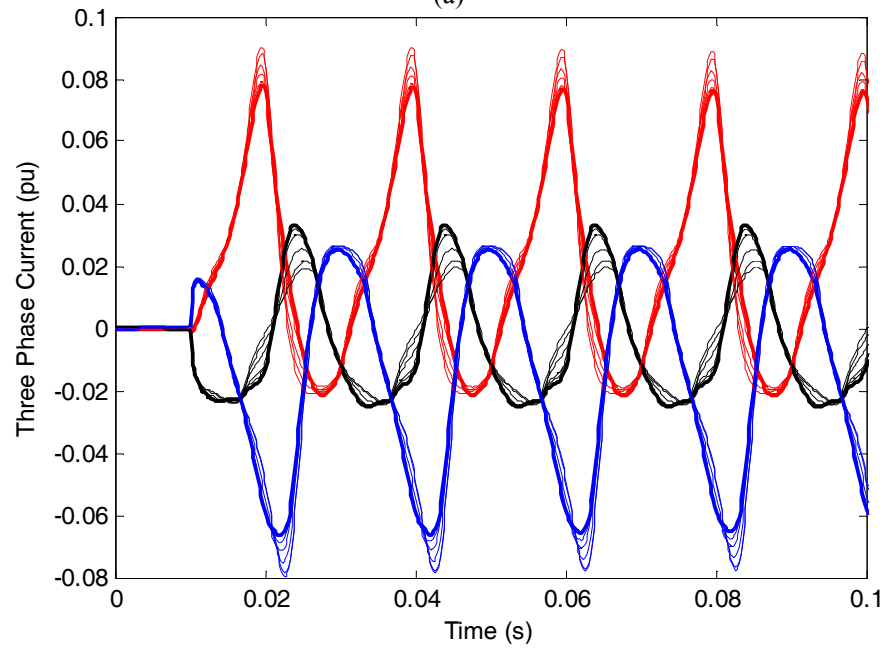

(b)

Fig. 4. Effects of magnetic core-leg flux couplings in asymmetric cores on three-phase inrush current waveform formation 

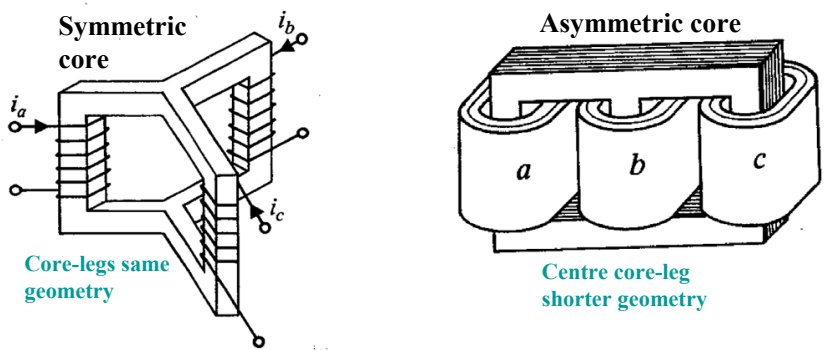

(a)

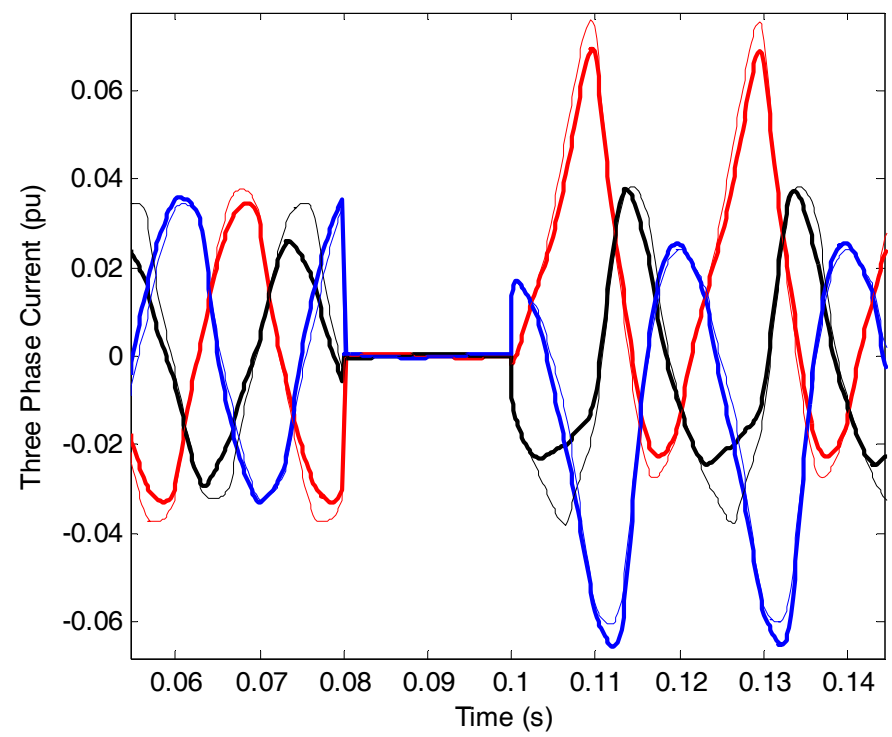

(b)

Fig. 5. Comparison of symmetrical (thin-lines) versus asymmetrical (thicklines) core structure effects (a) on transformer inrush current waveforms (b). Serious discrepancies can occur in inrush-current simulations if symmetrical core assumption is taken in the modeling of a three-phase transformer.

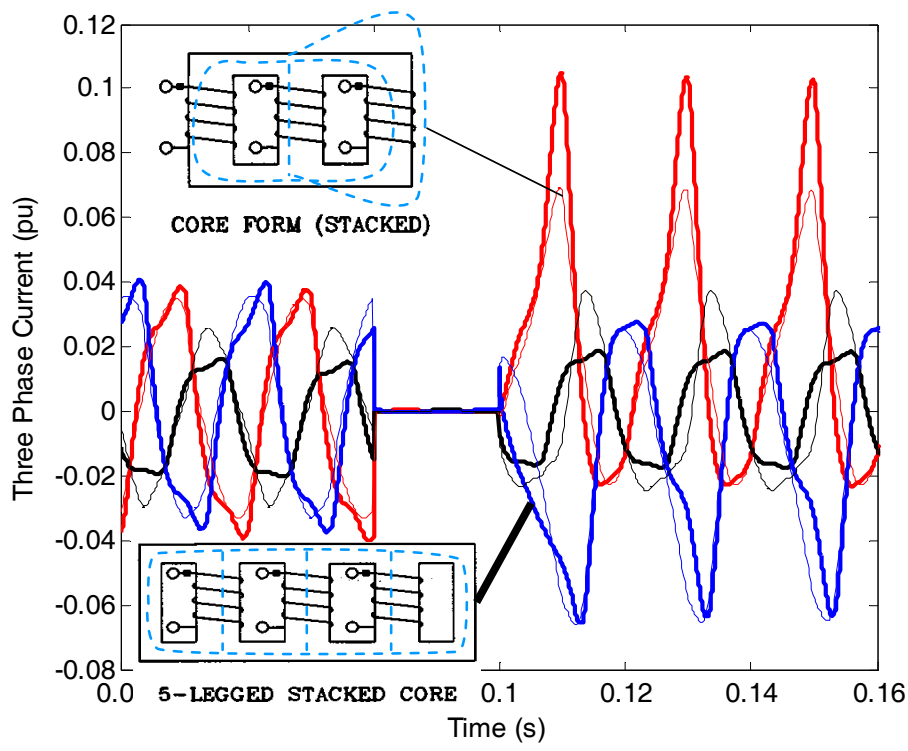

Fig. 6. Comparison of three-leg (thin-lines) versus five-leg (thick-lines) cores on three-phase inrush current waveforms. The different core-leg flux paths distributing in the iron-core can significantly affect inrush-current waveforms.
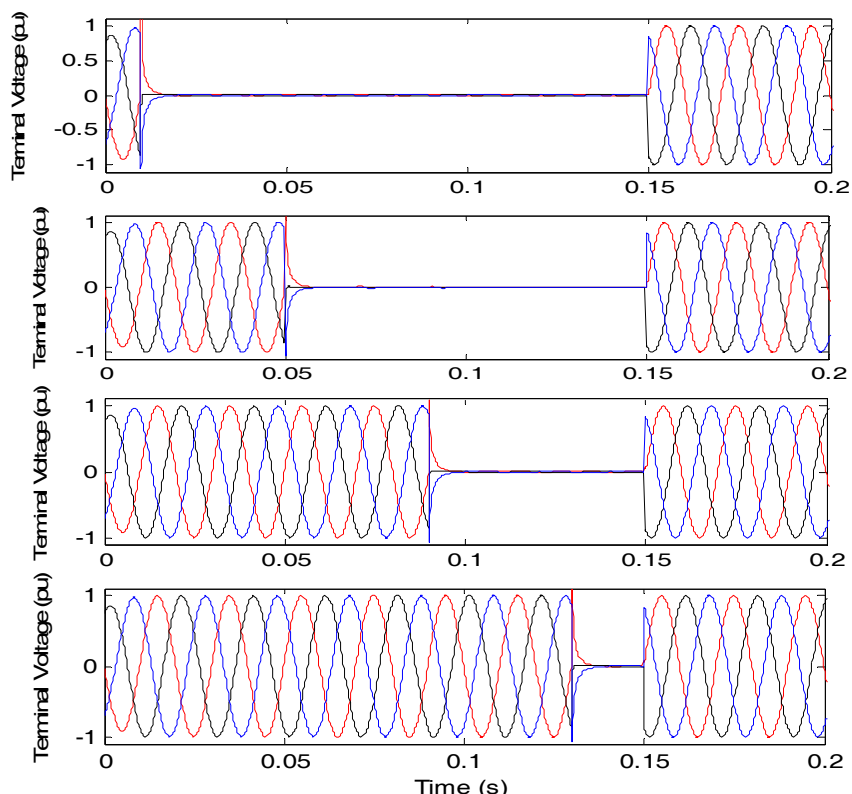

(a)

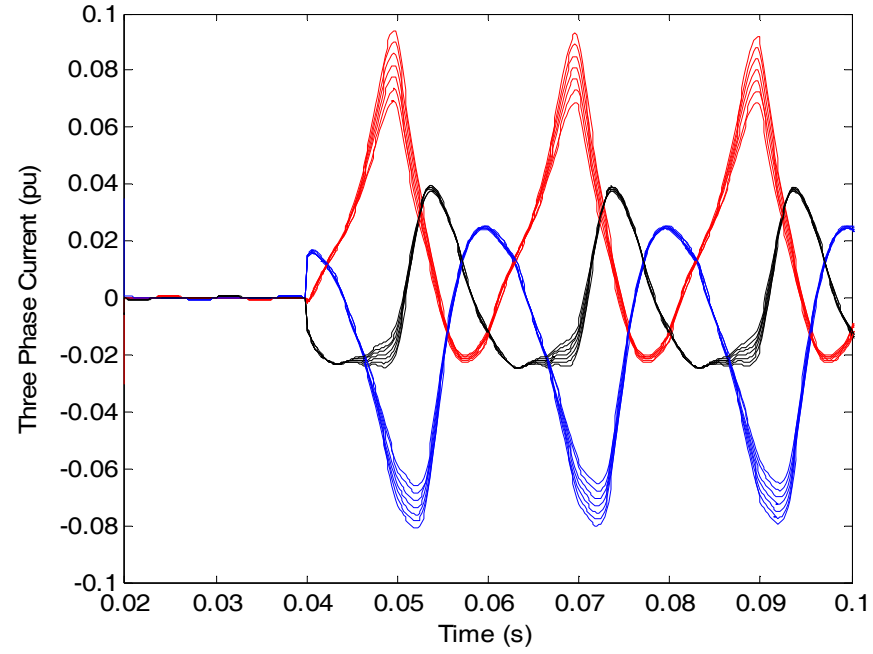

(b)

Fig. 7. Effect of recloser delay duration on inrush current magnitudes. Different recloser delays (a) have an effect on inrush current peaks (b) due to varying decay levels in core-leg fluxes during the recloser delay period.

\section{DISCUSSION}

The magnetic effects of multi-leg transformer core structures and electrical switching effects of reclosers on three-phase transformer inrush current behavior is discussed in this section. This is relevant due to the many different transformer types currently in service as well as the widespread use of automatic reclosers in distribution protection systems. It is important to understand their behavior under such conditions since transformer service life and reliability could be affected which could go unnoticed without sufficient detailed electromagnetic transient modeling studies. 


\section{A. Effect of Magnetic Couplings and Zero-Sequence Fluxes}

The effect of magnetic couplings of the fluxes in transformer cores on inrush current formation is simulated in Fig. 4. This is performed through variation of the zerosequence reluctance $\mathrm{R}_{0}$ which affects the flux path of the zerosequence component. If $\mathrm{R}_{0}$ is a very large value, the transformer model of Fig. 4 approximates a three-leg core with a very high reluctance air path (e.g., no magnetic tank). This means that the core-leg fluxes are contained mainly within the core and have strong couplings.

When $\mathrm{R}_{0}$ is reduced from this case, the zero-sequence flux has an increasingly easier path which is akin to a transformer core with 4 of 5 legs, or the presence of a tank structure. In the extreme case that $R_{0}$ is reduced to negligible values, this mimics a core where each of the wound core-legs are decoupled from one another such as a three single-phase transformer bank (Fig. 1, triplex core).

As shown in Fig. 4, different zero-sequence reluctances, and as a consequence, different levels of core-leg couplings, result in significant variations in three-phase inrush current waveforms. This can also affect the peak inrush current values which can damage transformer winding insulation and reduce service life.

\section{B. Effect of Symmetrical and Asymmetrical Core-Legs}

Due to different core topologies, it is possible that each of the wound core-legs could have different geometries affecting its magnetizing behavior. A three-leg core is such a case where the center leg is much shorter than the outer legs. This is known as an asymmetric core as depicted in Fig 5 which is largely ignored in transformer modeling studies. Asymmetric three-leg cores are often necessary since it requires the least amount of core material versus and has a more practical construction than building a symmetrical three-leg core (Fig. $5 a)$. Hence, investigating the inrush behavior in asymmetric cores is necessary to compare the validity of symmetrical core model assumptions.

The effects of assuming symmetrical core leg magnetizing behavior (i.e., identical core-leg B-H characteristics) versus the true asymmetric core leg magnetization effects in three-leg transformers are simulated in Fig. 5b. These results show a significant impact on inrush current waveform behavior upon transformer energization. The presence of asymmetry in the core by having a shorter center leg not only affects the inrush current in the phase winding of that leg, but due to the strong magnetic core couplings, it also affects the behavior of currents in other phases wound on the outer core-legs.

\section{Effect of Three-Leg vs. Five-Leg Cores}

A comparison of inrush currents in three-leg versus five-leg cores is simulated in Fig. 6. The five-leg core structure is approximated by repeating the nonlinearities in the model of the outer two-legs of the three-leg core to make a five-leg core. These results show that the inrush current peaks and wave-shapes are significantly different between the two core topologies due to the new distribution of core fluxes.

\section{Effect of Recloser Timings}

In Western Australia and many other networks worldwide, automatic reclosers are frequently employed in distribution systems. These special types of circuit breakers have the ability to attempt to reclose themselves after a preprogrammed time delay in case the fault has cleared itself (e.g., conductors clashing in high wind). So far, the (re)energization effects of distribution transformers downstream of the circuit breaker due to recloser operation have not been looked at closely.

The results of Fig. 7 depict how inrush current waveforms vary for different recloser delay settings ranging from 8 cycles down to 1 cycle. Wider time delays are possible between recloser events as well as multiple reclosing shots, however the effects on inrush currents can clearly be seen even for this simple one-shot reclosing action.

Results indicate that the longer the recloser delay, the worse the inrush current peak magnitudes can be. Since the recloser delays simulated are integer numbers of cycles, the points-onvoltage-wave that the recloser acts upon do not change and should not affect the inrush current waveforms. However, the residual flux in the transformer core can change and decay within this time which affects the inrush current behavior. For longer recloser delays, it can be observed the residual flux can decay sufficiently to change the transformer flux operating condition upon reconnection to worsen inrush currents.

\section{CONCLUSION}

The inrush current magnetizing behavior of three-phase multi-leg (e.g., three-leg and five-leg) transformers subject to different operating conditions is studied. The variation in core designs, core leg-flux couplings, (a)symmetry in the core structure and recloser switching events are examined. These results highlight the importance of further investigating and including the effects of key magnetic circuit properties in three-phase transformer models. The main conclusions are:

- Inrush current wave-shapes and peaks are strongly affected by the level of core-leg flux couplings and interactions present in three-phase magnetic circuits of different iron-core geometries.

- Most transient studies based on standard transformer models in simulation software adopt a "per-phase" modeling approach ignoring magnetic circuit effects. Therefore, researchers and engineers using that approach run the risk of overlooking detrimental transient effects such as underestimating inrush current peaks.

- The often ignored iron-core asymmetry in three-phase electromagnetic studies significantly influences legcouplings and inrush current wave-shapes and peaks.

- Recloser events on re-energization behavior of three-phase transformers deserve further attention in future work. As shown in this preliminary study, different one-shot recloser events may influence transformer inrush currents affecting protection systems and could cause transformer damage. The effect of multiple reclosing shots with different recloser delays should be investigated in future work. 


\section{REFERENCES}

[1] "The evolution of power transformers: 110 years of power transformer technology ", 2011. [Online]. Available: http://www.abbaustralia.com.au/cawp/db0003db002698/1d5674d76939 7bc8c12572f40045bd75.aspx.

[2] H. Iman-Eini, J. Schanen, S. Farhangi, J. Barbaroux, and J. Keradec, "A power electronic based transformer for feeding sensitive loads," in Proc. IEEE Power Electronics Specialists Conference (PESC), 2008, pp. 2549-2555.

[3] E. R. Ronan, S. D. Sudhoff, S. F. Glover, and D. L. Galloway, "A power electronic-based distribution transformer," IEEE Transactions on Power Delivery, vol. 17, no. 2, pp. 537-543, 2002.

[4] S. Deilami, A. Masoum, P. S. Moses, and M. A. S. Masoum, "Real-time coordination of Plug-In Electric Vehicle charging in smart grids to minimize power losses and improve voltage profile," IEEE Transactions on Smart Grid, vol. 2, no. 3, pp. 456-467, 2011.

[5] S. Massoud Amin and B. F. Wollenberg, "Toward a smart grid: power delivery for the 21st century," IEEE Power and Energy Magazine, vol. 3, no. 5, pp. 34-41, 2005.

[6] E. F. Fuchs and M. A. S. Masoum, Power quality in power systems and electrical machines: Academic Press/Elsevier, 2008.

[7] E. F. Fuchs and M. A. S. Masoum, Power conversion of renewable energy systems: Academic Press/Springer, 2011.

[8] P. S. Moses, M. A. S. Masoum, and H. A. Toliyat, "Dynamic modeling of three-phase asymmetric power transformers with magnetic hysteresis: no-load and inrush conditions," IEEE Transactions on Energy Conversion, vol. 25, no. 4, pp. 1040-1047, 2010.

[9] P. S. Moses, M. A. S. Masoum, and H. A. Toliyat, "Impacts of hysteresis and magnetic couplings on the stability domain of ferroresonance in asymmetric three-phase three-leg transformers," IEEE Transactions on Energy Conversion, vol. 26, no. 2, pp. 581-592, 2011.

[10] M. A. S. Masoum and P. S. Moses, "Impact of balanced and unbalanced direct current bias on harmonic distortion generated by asymmetric three-phase three-leg transformers," IET Electric Power Applications, vol. 4, no. 7, pp. 507-515, 2010.

[11] M. R. Iravani, A. K. S. Chaudhary, W. J. Giesbrecht, I. E. Hassan, A. J. F. Keri, K. C. Lee, J. A. Martinez, A. S. Morched, B. A. Mork, M. Parniani, A. Sharshar, D. Shirmohammadi, R. A. Walling, and D. A. Woodford, "Modeling and analysis guidelines for slow transients-Part III. The study of ferroresonance," IEEE Transactions on Power Delivery, vol. 15, no. 1, pp. 255-265, 2000.

[12] E. F. Fuchs, Y. You, and D. J. Roesler, "Modeling and simulation, and their validation of three-phase transformers with three legs under DC bias," IEEE Transactions on Power Delivery, vol. 14, no. 2, pp. 443449, 1999.

[13] E. C. Cherry, "The duality between interlinked electric and magnetic circuits and the formation of transformer equivalent circuits," Proc. Phys. Soc., vol. 62, 1949.
[14] G. Chang, C. Hatziadoniu, W. Xu, P. Ribeiro, R. Burch, W. M. Grady, M. Halpin, Y. Liu, S. Ranade, D. Ruthman, N. Watson, T. Ortmeyer, J. Wikston, A. Medina, A. Testa, R. Gardinier, V. Dinavahi, F. Acram, and P. Lehn, "Modeling devices with nonlinear voltage-current characteristics for harmonic studies," IEEE Transactions on Power Delivery, vol. 19, no. 4, pp. 1802-1811, 2004.

[15] J. Tellinen, "A simple scalar model for magnetic hysteresis," IEEE Transactions on Magnetics, vol. 34, no. 4, pp. 2200-2206, 1998.

Paul S. Moses ( $\left.\mathrm{S}^{\prime} 09\right)$ received his B. Eng. $\left(1^{\text {st }}\right.$ Class Hons.) and B. Sc. degrees in Electrical Engineering and Physics in 2006 from Curtin University of Technology, Perth, Australia. He received the W. J. Smith Memorial Prize for Best Electrical Engineering Honors Thesis and the Don Watts Prize from the Faculty of Engineering for the most innovative research project. He was awarded an Australian Postgraduate Award scholarship in 2009 and is presently working towards a Ph. D. degree in Electrical Engineering at Curtin University of Technology. He is also a Research Scientist for the Research Scientist for the Defence Science and Technology Organization (DSTO), Department of Defence, HMAS Stirling, Australia, and is presently part of their Maritime Platforms Division, Propulsion and Energy Systems Group. His research interests include nonlinear electromagnetic phenomena, power quality and protection.

Mohammad A.S. Masoum (SM'05) received his B.S., M.S. and Ph.D. degrees in Electrical and Computer Engineering in 1983, 1985, and 1991, respectively, from the University of Colorado at Boulder, USA. He is currently an Associate Professor and the Discipline Leader for Electrical Power Engineering at the Electrical and Computer Engineering Department, Curtin University, Perth, Australia. His research interests include optimization, power quality and stability of power systems/electric machines, and distributed generation. Dr. Masoum is the coauthor of "Power Quality in Power Systems and Electrical Machines" (Elsevier, 2008) and "Power Conversion of Renewable Energy Systems" (Springer, 2011). He is a senior member of IEEE.

Moayed Moghbel graduated with a B.S. degree in Electrical Engineering from Khomeinishahr Azad University from Iran in 2003. He is currently a Masters student in Electrical Engineering at Curtin University, Perth, Australia. He has 4 years experience in a petrochemical company as an electrical maintenance engineer and 1 year as a distribution project manager. My interests include power quality, protection and electrical machines. 